\title{
Monitoring manufacturing of composites using embedded distributed optical fibre sensors
}

Link to publication record in Manchester Research Explorer

\section{Citation for published version (APA):}

Martínez Sánchez, D., Gresil, M., \& Soutis, C. (2015). Monitoring manufacturing of composites using embedded distributed optical fibre sensors. In 10th International Workshop on Structural Health Monitoring

\section{Published in:}

10th International Workshop on Structural Health Monitoring

\section{Citing this paper}

Please note that where the full-text provided on Manchester Research Explorer is the Author Accepted Manuscript or Proof version this may differ from the final Published version. If citing, it is advised that you check and use the publisher's definitive version.

\section{General rights}

Copyright and moral rights for the publications made accessible in the Research Explorer are retained by the authors and/or other copyright owners and it is a condition of accessing publications that users recognise and abide by the legal requirements associated with these rights.

\section{Takedown policy}

If you believe that this document breaches copyright please refer to the University of Manchester's Takedown Procedures [http://man.ac.uk/04Y6Bo] or contact uml.scholarlycommunications@manchester.ac.uk providing relevant details, so we can investigate your claim.

\section{OPEN ACCESS}




\section{COVER SHEET}

Title: Monitoring manufacturing of composites using embedded distributed optical fibre sensors

Authors: Daniel Martínez Sánchez

Matthieu Gresil

Constantinos Soutis

Proceedings of the $\mathbf{1 0}^{\text {th }}$ International Workshop on Structural Health Monitoring 2015 
(FIRST PAGE OF ARTICLE)

\begin{abstract}
After manufacturing a composite element, it is expected to have residual stresses which affect the quality and the mechanical properties of the composite. In the present work, a distributed optical fibre sensor (DOFS) was embedded in a carbon fibre panel, measuring the development of residual stresses by monitoring in real-time the manufacturing process, from the resin infusion to the curing cycle, and the changes experienced within. An optical sensor interrogator detects and measures changes in strain and temperature along the DOFS with high precision and accuracy, making it possible to obtain a full strain/temperature profile. Data acquired from the embedded sensor led to track and characterize the strain profile at every stage of the manufacture process.
\end{abstract}

\title{
INTRODUCTION
}

During the last decades, usage of composite materials had a noticeable increase with a huge impact on countless applications. Fibre reinforced polymers (FRP) are a well-known example of engineering materials, which its high strength and low density properties, primarily, make them clearly attractive for use in transport, infrastructure, energy and aerospace industries [1]. For such purposes several manufacturing techniques and processes had been developed [2] in order to extend shape's limits, improve the final product's quality, increase volume production and lower costs as well. However, due to epoxy resins chemical properties, physical reactions take place during cure process, resulting in the build-up of internal stresses and volume change in the composite structures [3]. Interest has been increasing to monitor the manufacturing process, in which by most, manufacturing parameters are solely followed and controlled (pressure, temperature, etc.).

Daniel Martínez Sánchez, School of Materials, University of Manchester, UK

Matthieu Gresil, School of Materials, University of Manchester, UK.

Constantinos Soutis, Aerospace Research Institute, University of Manchester, UK. 
Strain gages, amongst other sensors, had been largely employed to monitor the curing stages in the fabrication of FRP components and, in the last 20 years, optical fibre sensors (OFSs) had been incorporated to provide a non-invasive in situ channel to track in real time the composites' behaviour while being manufactured and even after at operational conditions [1, 2, 4-9]. Despite the employment of either strain gages or OFSs (fibre Bragg grating or extrinsic Fabry-Pérot interferometric sensors) for cure monitoring [10], the information obtained from these sensors is only punctual and cannot cover a larger sensing region.

The present work shows the implementation of distributed optical fibre sensors (DOFS) into a carbon fibre reinforced polymer (CFRP) panel to monitor its manufacturing process. The information concerning residual stress was acquired providing a stress profile along the panel throughout the curing step and thus exhibits the advantages of using this sensor.

\section{DISTRIBUTED OPTICAL FIBRE SENSORS (DOFS)}

Distributed sensing with an optical fibre is possible through the interrogator's capacity to detect physical changes in the fibre's core, being Rayleigh backscattering the key parameter to be measured and analysed. The molecular arrangement from the optical fibre is unique like a "fingerprint" for every fibre, and determines the fibre's index profile and thus the way in which an input light will backscatter along the fibre [11]. Since Rayleigh scattering deals with particles smaller than the light's wavelength, its interaction does not appreciably change the phase or amplitude of the light wave [12]. Shifts in the frequency response take place due to mechanical and/or thermal stimuli. Because frequency variations are proportional to induced strain or change in temperature, a comparison between a previous state and the actual fibre's condition can be performed and hence measure the strain or temperature changes, just like a fibre Bragg grating (FBG) sensor $[13,14]$.

\section{MATERIALS AND EXPERIMENTAL SETUP}

Epoxy resin was employed as the matrix, reinforced by twilled carbon fibre fabric plies, melded by means of a vacuum assisted resin infusion moulding (VARIM) technique using a stainless steel flat mould [15].

A two-metre, single-mode, low-bend-loss, polyimide coated silica glass optical fibre sensor was used in the experiment. Distributed stress data was acquired from the sensor via an optical frequency domain reflectometry (OFDR) based interrogator from LUNA Technologies (ODiSI-B model). In addition to this, temperature along the curing process was recorded with a pair of K-Type thermocouples.

Six 400x200 mm plies of twilled carbon fibre were cut and marked individually to ease the optical sensor embedment. The optical fibre position required a careful insertion between the composite's layers (Figure 1). With help of a common pin, the optical sensor could be safely attached and positioned where desired without using glue or any bonding aid, either by creating small openings between the carbon fibres to let the sensor pierce through the plies or by lifting crossed fibres to be threaded with the sensor, ensuring its fixed position.

Optical fibre embedment was performed from the top layer down to the bottom layer, so that the input side ended on top of the panel. Three main straight parallel 
sensing regions were defined, allocating the first one (referred to as "Top Layer") between the fifth and the sixth plies (counting from bottom to top); the second region between the third and the fourth plies (Middle Layer); and the last one is localised between the first and second plies (Bottom Layer). Each sensing region is $50 \mathrm{~mm}$ separated from each other and from the panel edges; and about $300 \mathrm{~mm}$ long each, holding 460 sensors with a gage length of $1.25 \mathrm{~mm}$. The portion of the OFS embedded in the panel was completely bare fibre, allowing it to fully interact with the composite and its changes along the manufacturing process. The outer portion of the sensor was protected with a Teflon capillary tube, obtaining this way a mechanical-stress-free region (only thermal effects affected this part of the optical fibre), covering from the sensor connector to $5 \mathrm{~mm}$ inside the panel, minding the sensor's access and to avoid its breakage.
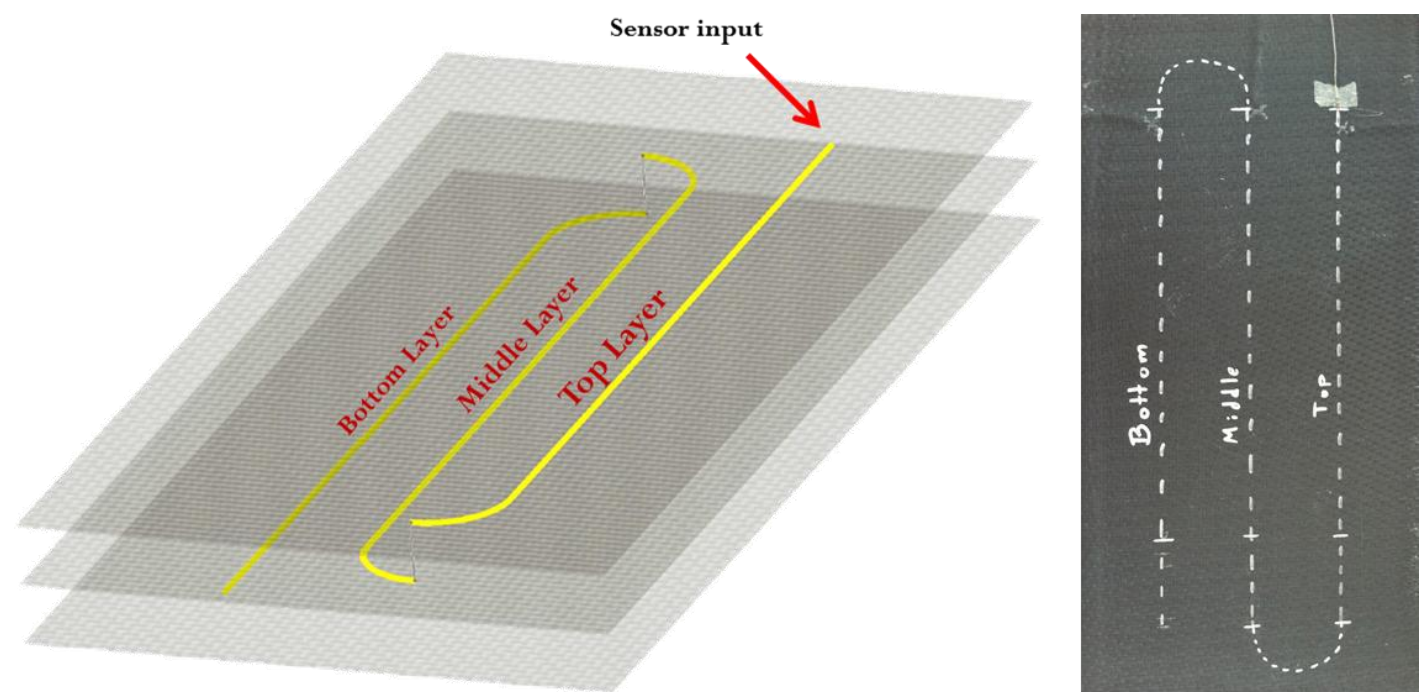

Figure 1: Schematic of the OFS location inside the composite panel (left) and top view of the finished panel with the OFS path traced.

Moreover, a thermocouple was attached to the composite preform, embedding it close to the top sensing region. This sensor registered the temperature within the infused panel during the cure cycle. Resin infusion was performed at room temperature $\left(\sim 20^{\circ} \mathrm{C}\right)$ and the strain from the optical fibre was monitored every minute during the process. This helped to follow the resin flow through the thickness of the panel by noticing strain changes in the different sensing regions, making sure that all the carbon fibre layers were fully wet, especially the ones at the bottom of the stack. Example of this can be observed in Figure 2. The infusion process lasted near 20 minutes and Figure $2 \mathrm{a}$ shows the strain profile, and hence the resin distribution past ten minutes since the vacuum pump was turned on. In Figure $2 b$, it is noticed a nonuniform strain profile achieved after the infusion, probably produced by an uneven resin distribution which showed a preference to flow close to the panel's edges over the infusion. At the end, a higher concentration of resin is found at the transversal sides of the panel (with strain up to $300 \mu \varepsilon$ ) in comparison with the central area. Later the resin distribution will be homogenized during the curing process. 

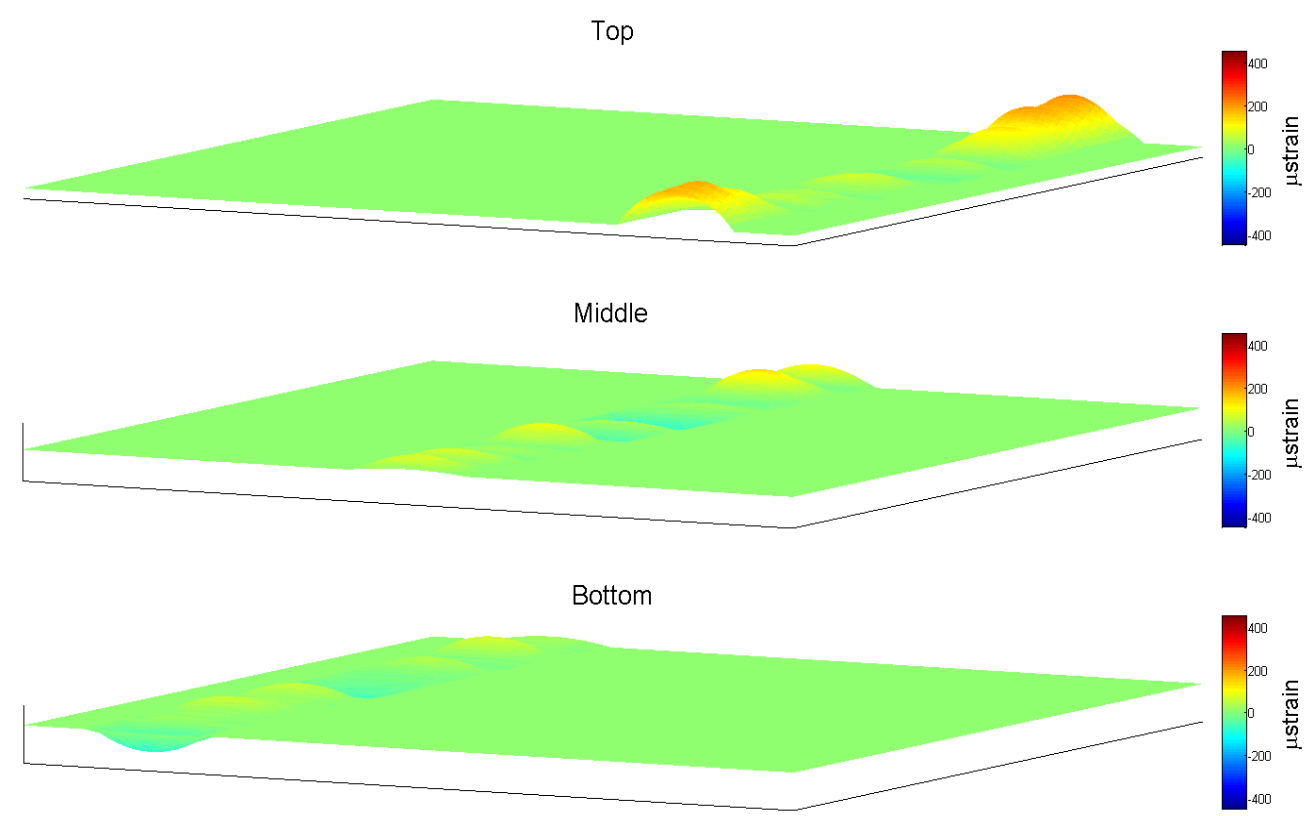

(a)
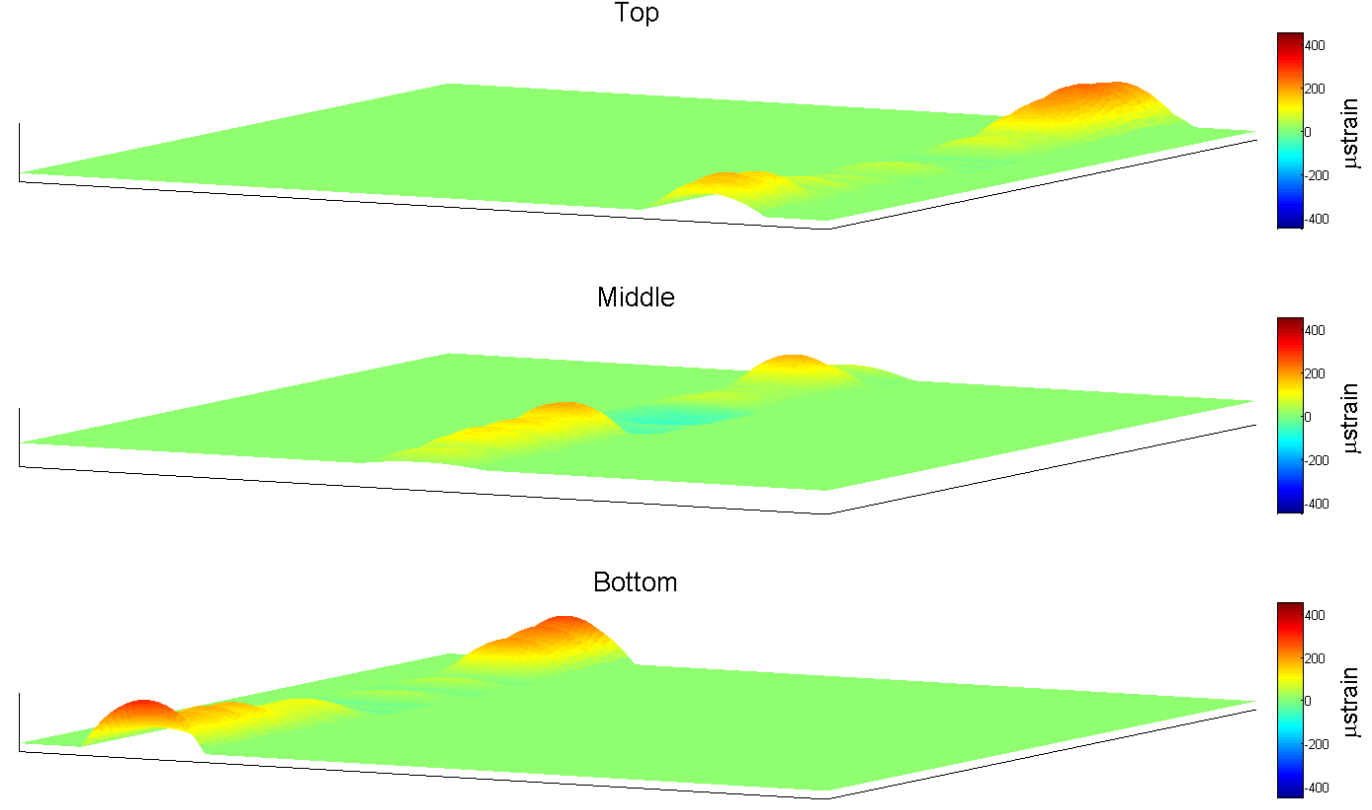

(b)

Figure 2: Distributed strain profile during resin infusion at the different level in the composites stack: (a) during resin infusion; (b) after resin infusion.

The selected cure cycle consisted of a first rise from room temperature to $80^{\circ} \mathrm{C}$, holding it for 1 hour before heating up again to $160^{\circ} \mathrm{C}$. After holding the curing oven at $160^{\circ} \mathrm{C}$ for two hours, the oven was turned off and the panel was left inside to allow an extended cooling period and thus monitor the composite's strain behaviour throughout the entire curing process.

Thermal effects had to be removed from the total strain acquired with the OFS in order to calculate only the mechanical strain. It is assumed that the portion of the OFS which remains outside the vacuum bag is only experience thermal stress due to the material dilation, consequence of the rise in temperature inside the oven [16]. This 
thermal-dependant section was also monitored and later used as reference of the thermal effects within the sensor, thereby removing the strain induced only by the change in temperature.

$$
\text { Mechanical strain = Total strain }- \text { Thermal strain }
$$

This equation is valid whenever significant variations in temperature take place, otherwise, thermal effects become negligible compared to strain measurement.

\section{RESULTS \& DISCUSSION}

During the curing process, the physical interaction between the optical sensor and the composite panel, in addition to the thermal expansion of the sensor itself, resulted in the graph shown in Figure 3. The total strain measured along each sensing region behaved in almost an identical way in every segment, therefore an average of the total strain behaviour is presented in a single graph for the entire panel. It is clearly seen how the strain experienced by the optical sensor is related to temperature's variations from the thermocouple.

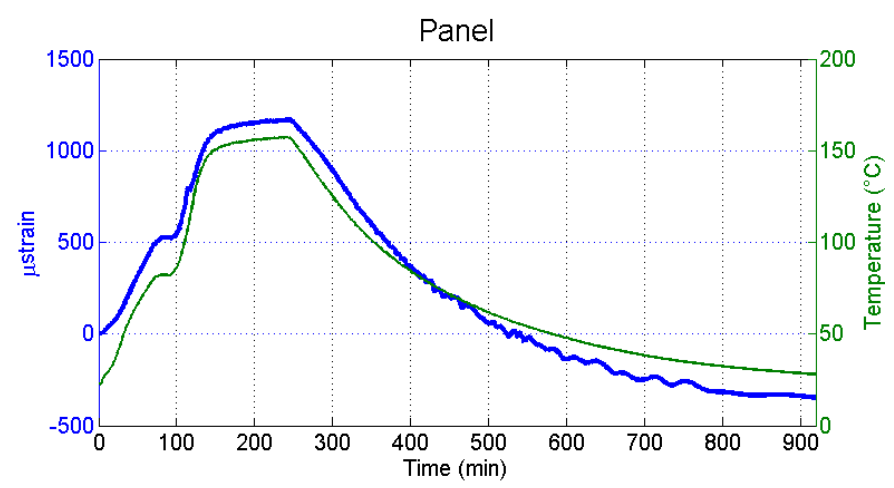

Figure 3: Average strain during curing cycle between the three sensing regions (mechanical and thermal effects together) (in blue: DOFS reading; green: thermocouple).

When separating the strain produced by the thermal expansion of the OFS from the total strain measured, the mechanical strain associated to the physical effects inside the composite panel is left. As shown in the graphs at Figure 4, the interior of the composite element, at every layer analysed, experiences in average only compressive strain effects over the curing and cooling stages. However, even where it seems to have the same strain behaviour between the panel's layers, it is noticeable at the cooling step certain variations different from one layer to the other, despite of sharing the same tendency, being the bottom and middle layers which show a guided disturbed behaviour different from the top, in which case its behaviour looks smoother. This is probably because of the interaction between the steel mould and the bottom of the panel, as result of the differing coefficient of thermal expansion from each material and some "intermittent sliding" of the sample while the last shrinkage of the composite takes place. Even so, the resin matrix behaviour resulted as expected in comparison with related works [1-3, 6, 7], easily appreciating how the resin finishes to fill every remaining gap between the carbon fibre plies when its viscosity is lowered (below $80^{\circ} \mathrm{C}$ ), promoting an overall strain relief before turning into gel (at $80^{\circ} \mathrm{C}$ ), when compressive strain is built up leading to the vitrification stage at the glass 
transition temperature (around $130^{\circ} \mathrm{C}$ for this epoxy resin and hardener employed in the experiment).
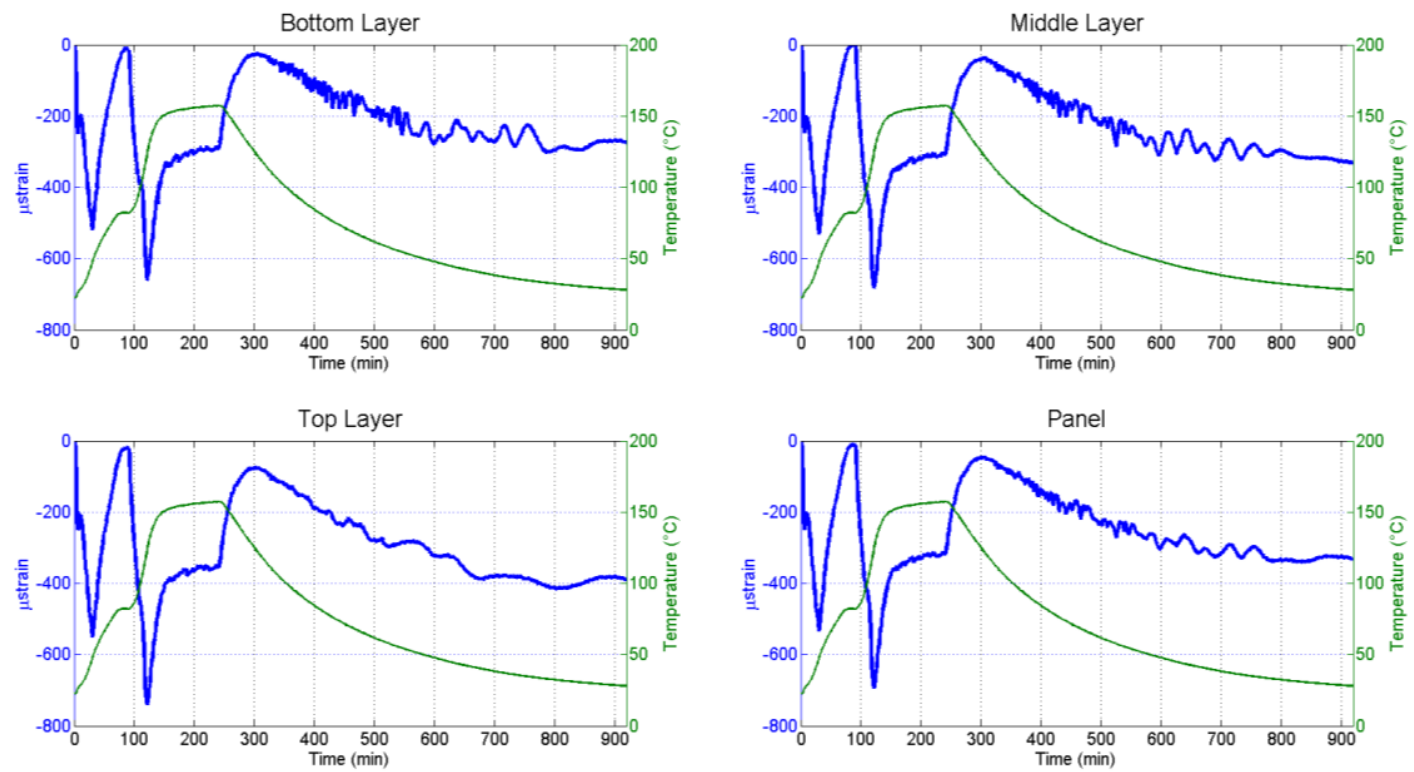

Figure 4: Average mechanical strain measured in each sensing region and within the panel during curing cycle.

An evident down peak of compressive strain appears right when the resin reaches such temperature and then the matrix experiences then a slight shrinkage accompanied with a small decrement in the strain previously reached, keeping a steady strain until the end of the second dwell. Thereafter, before the cooling stage, the detachment of the panel from the mould occurs, showing a noticeable decrement in the compressive strain leading almost to a neutral condition and allowing then a gradual contraction carrying the final residual strain obtained at the end of the manufacturing process.

Finally, the residual stress is now presented. Figure 5 shows the map of the residual stress profile through the different sensing regions resulting in an overall compressed composite, due to the shrinking nature of the epoxy matrix. It is highly remarkable a certain strain agreement between each sensing region. Even more, by averaging the compressive strain for each layer, values of $-405,-347,-291 \mu \varepsilon$ were obtained for the top, middle and bottom layers, respectively, resulting in a difference of $\sim 60 \mu \varepsilon(\sim 15 \%)$ between regions.

Figure 6 shows how the strain signal from the OFS was divided in segments and the main sensing regions assigned. Note that between each major signal segment; the strain reading behaves considerably different compared to the adjacent readings. These small segments of the distributed measurement belong to the bent sections of the OFS, where added to the axial strain effects, transversal and thereby mixed strain effects affect together, making it harder to analyse and understand what is happening in these zones. This is the reason why studies were only performed on the straight sections of the optical sensor. Nevertheless, it has been noticed a possible relationship between the resulting residual strain and the profile seen after the resin infusion, bringing in the hypothesis that the status of the composite once infused will somehow prevail and promote the way in which residual stress will develop over the curing process. 

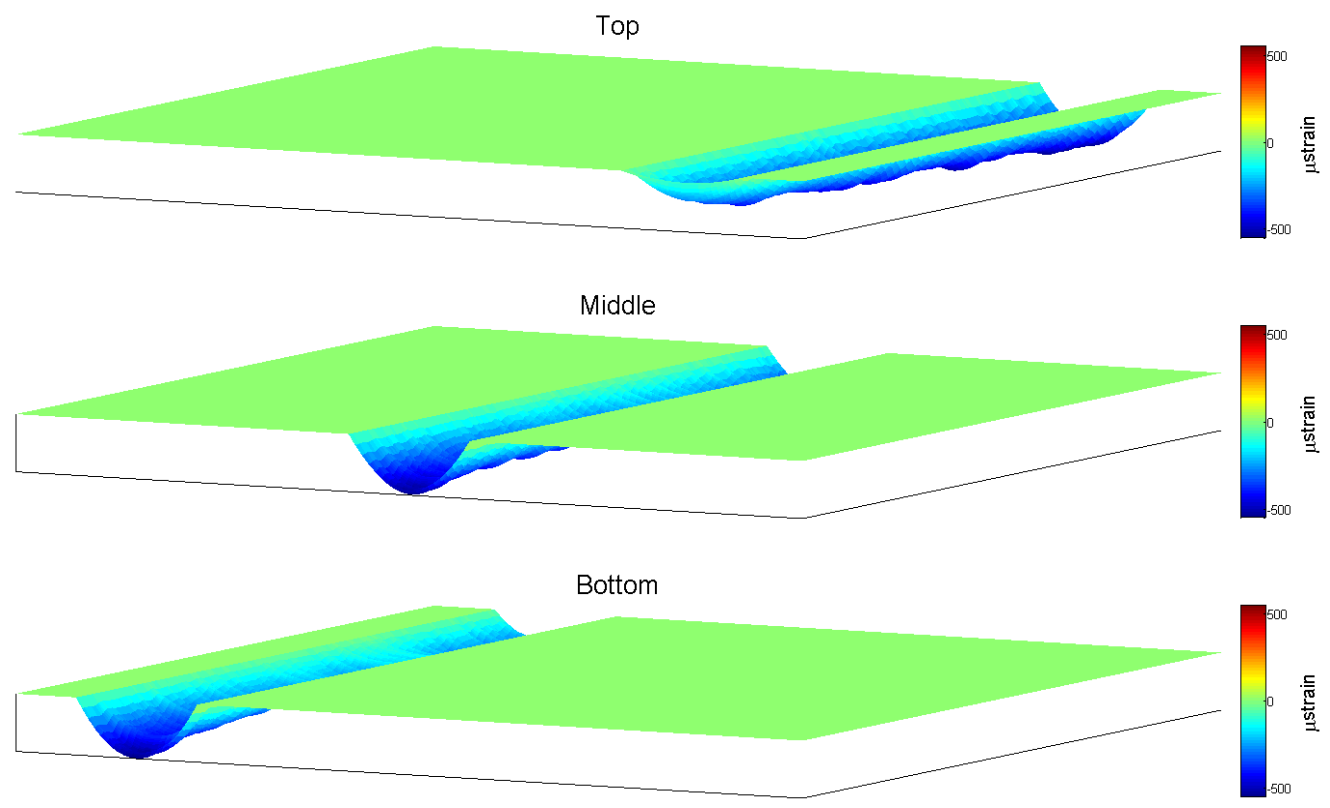

Figure 5: Residual strain profile at each sensing region.

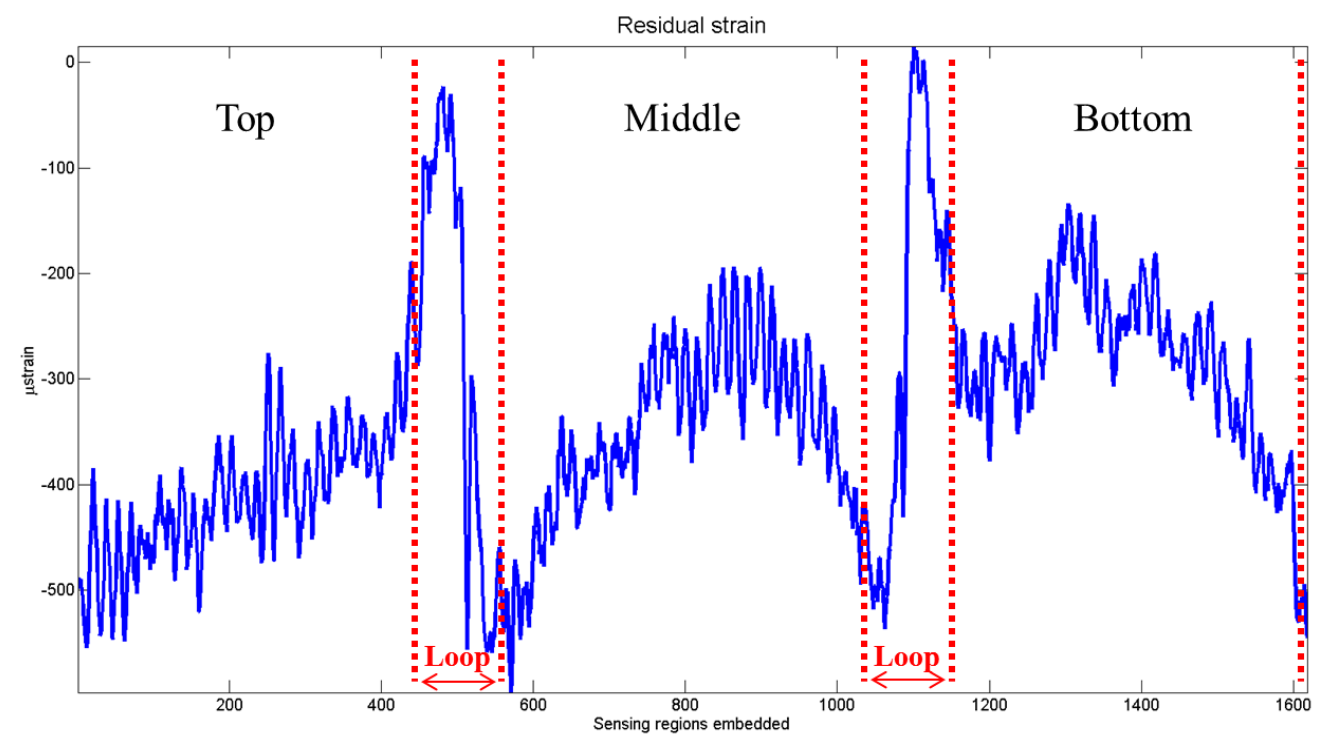

Figure 6: Residual strain signal for the embedded portion of the DOFS with the main sensing regions highlighted.

\section{CONCLUDING REMARKS}

Real-time distributed strain monitoring during the manufacture process of a CFRP panel was performed. The DOFS resulted to be an excellent and accurate way to keep track of the strain induced along the composite panel throughout the different manufacturing stages. The results obtained seemed similar to those from Crasto [5] and Oliveira [3], showing the same strain behaviour tendency and effects occurred particularly at the cure step. Monitor measurement and mapping of the distributed residual strain profile was successfully achieved. With the results discussed in the present work, it is once again remarked the importance of composite manufacture monitoring, specifically with fully distributed sensors, which can give useful 
information about the condition of the composite panel at several point through the length, width and thickness whenever it is required, in order to follow the distribution of the resin, its physical changes and the effects this has within the composite material. This data can then be used to have a better understanding of all the internal changes and behaviour and subsequently manage to control the manufacturing process in such way that distributed residual stresses are minimized and study its effects on mechanical properties. Further work is required to make a deeper study and characterization of internal strain and product quality of CFRP components, as well as mechanical tests to determine the relation between the manufacture results and the mechanical behaviour.

\section{REFERENCES}

1. Ferdinand, P., et al., Applications of fiber Bragg grating sensors in the composite industry. MRS Bulletin, 2002. 27(05): p. 400-407.

2. $\quad$ Kang, H.-K., et al., Cure monitoring of composite laminates using fiber optic sensors. Smart materials and structures, 2002. 11(2): p. 279.

3. De Oliveira, R., et al., Experimental investigation of the effect of the mould thermal expansion on the development of internal stresses during carbon fibre composite processing. Composites Part A: Applied Science and Manufacturing, 2008. 39(7): p. 1083-1090.

4. Yoo, S.-H., et al., Simulation of curing process of carbon/epoxy composite during autoclave degassing molding by considering phase changes of epoxy resin. Composites Part B: Engineering, 2015. 77: p. 257-267.

5. Crasto, A.S., R.Y. Kim, and J.D. Russell, In situ monitoring of residual strain development during composite cure. Polymer composites, 2002. 23(3): p. 454-463.

6. $\quad$ Khoun, L., et al., Investigation of process-induced strains development by fibre Bragg grating sensors in resin transfer moulded composites. Composites Part A: Applied Science and Manufacturing, 2011. 42(3): p. 274-282.

7. Kang, H.-K., et al., Simultaneous monitoring of strain and temperature during and after cure of unsymmetric composite laminate using fibre-optic sensors. Smart materials and structures, 2003. 12(1): p. 29.

8. Huang, C., et al. Simultaneous temperature and strain monitoring of composite cure using a Brillouin-scattering-based distributed fiber optic sensor. in SPIE's 8th Annual International Symposium on Smart Structures and Materials. 2001. International Society for Optics and Photonics.

9. $\quad$ Murukeshan, V., et al., Cure monitoring of smart composites using fiber Bragg grating based embedded sensors. Sensors and Actuators A: Physical, 2000. 79(2): p. 153-161.

10. Leng, J. and A. Asundi, Structural health monitoring of smart composite materials by using EFPI and FBG sensors. Sensors and Actuators A: Physical, 2003. 103(3): p. 330-340.

11. Samiec, D., Distributed fibre-optic temperature and strain measurement with extremely high spatial resolution. Photonik International, 2012(I): p. 10-13.

12. Vaezi-Nejad, S.M. and I.o.E. Engineers, Selected Topics in Advanced Solid State and Fibre Optic Sensors. 2000: Institution of Engineering and Technology.

13. Bos, J., et al. Fiber optic strain, temperature and shape sensing via OFDR for ground, air and space applications. in SPIE Optical Engineering + Applications. 2013. International Society for Optics and Photonics.

14. Güemes, A., A. Fernández-López, and B. Soller, Optical fiber distributed sensing-physical principles and applications. Structural Health Monitoring, 2010.

15. Goren, A. and C. Atas, Manufacturing of polymer matrix composites using vacuum assisted resin infusion molding. Archives of materials Science and Engineering, 2008. 34(2): p. 117120.

16. Luna Distributed Fiber Optic Sensing: Temperature Compensation of Strain Measurement. Engineering Notes, Product Literature, 2014. 7. 